\title{
Yield Responses of Black Spruce to Forest Vegetation Management Treatments: Initial Responses and Rotational Projections
}

\author{
Peter F. Newton \\ Canadian Wood Fibre Centre, Canadian Forest Service, Natural Resources Canada, Sault Ste. Marie, ON, Canada P6A 2E5 \\ Correspondence should be addressed to Peter F. Newton, pnewton@nrcan.gc.ca \\ Received 9 June 2011; Revised 17 August 2011; Accepted 4 October 2011 \\ Academic Editor: John Sessions \\ Copyright () 2012 Peter F. Newton. This is an open access article distributed under the Creative Commons Attribution License, \\ which permits unrestricted use, distribution, and reproduction in any medium, provided the original work is properly cited.
}

The objectives of this study were to (1) quantitatively summarize the early yield responses of black spruce (Picea mariana (Mill.) B.S.P.) to forest vegetation management (FVM) treatments through a meta-analytical review of the scientific literature, and (2) given (1), estimate the rotational consequences of these responses through model simulation. Based on a fixed-effects metaanalytic approach using 44 treated-control yield pairs derived from 12 experiments situated throughout the Great Lakes-St. Lawrence and Canadian Boreal Forest Regions, the resultant mean effect size (response ratio) and associated 95\% confidence interval for basal diameter, total height, stem volume, and survival responses, were respectively: 54.7\% (95\% confidence limits (lower/upper): $34.8 / 77.6), 27.3 \%$ (15.7/40.0), 198.7\% (70.3/423.5), and 2.9\% (-5.5/11.8). The results also indicated that early and repeated treatments will yield the largest gains in terms of mean tree size and survival. Rotational simulations indicated that FVM treatments resulted in gains in stand-level operability (e.g., reductions of 9 and $5 \mathrm{yr}$ for plantations established on poor-medium and good-excellent site qualities, resp.). The challenge of maintaining coniferous forest cover on recently disturbed sites, attaining statutory-defined free-to-grow status, and ensuring long-term productivity, suggest that FVM will continue to be an essential silvicultural treatment option when managing black spruce plantations.

\section{Introduction}

The underlying objective of intensive forest management (IFM) is to increase the intrinsic productivity of the forest land base via the application of an integrated silvicultural regime involving the application of various temporal-spatialspecific treatment matrices encompassing intensive site preparation (e.g., mechanical scarification), plantation establishment including the use of genetically improved stock, eliminating competing vegetation via mechanical, chemical, or biological control mechanisms, continuous and active protection from insects and pathogens, and density management (e.g., maximizing product quality and quantity via initial spacing, precommercial thinning, and/or commercial thinning). At the forest level, these stand-level increases in productivity when translated into accelerated rates of development can be used to offset future wood supply deficits or increase the annual allowable cut through the annual allowable cut effect [1]. Although numerous case studies of individual experiments have clearly demonstrated the bene- fits of IFM treatments, collective summaries documenting the response of boreal species are limited. Consequently, as part of a larger quantitative synthesis regarding yield responses of boreal conifers to IFM treatments (e.g., tree improvement [2], forest fertilization [3], density management [4]), the objectives of this study were to (1) quantitatively summarize the early yield responses of black spruce (Picea mariana (Mill.) BSP) to forest vegetation management (FVM) treatments through a meta-analytical review of the scientific literature, and (2) given (1), project rotational outcomes of these responses employing a modified variant of the comprehensive growth, yield, and wood quality simulator, CROPLANNER $[5,6]$.

FVM has been defined as the practice of preferentially allocating the finite environmental resources (e.g., solar radiation, nutrients, and water) of a given site towards the selected crop tree species and away from noncrop species via the suppression, reduction, or elimination of the unwanted competitors, in order to realize specified silviculture and/or forest management objectives (sensu Walstad and Kuch [7]; 
Wagner et al. [8]; Bell et al. [9]). FVM can increase the likelihood of successful plantation establishment and assist in attaining statutory-defined free-to-grow status. Conversely, without FVM, forest managers may have difficulty in realizing their stand-level timber management objectives given the negative effect of herbaceous and woody competitors on the growth and survival rates of various crop species. Historically, the dominant means for controlling competing vegetation in Canada has been through the use of herbicides (e.g., aerial applications of glyphosate [10]). However, concern regarding the potential negative impacts of herbicide applications on wildlife habitat and biodiversity has resulted in numerous studies exploring various alternatives (e.g., [11-16]). Furthermore, the use of chemical herbicides has been prohibited in some regions (e.g., Canadian province of Quebec), and resistance to their use has been growing elsewhere (e.g., Europe [17]). Consequently, the focus of this study was to document the yield consequences of reducing or eliminating interspecific competitors on black spruce, irrespective of the actual control mechanism employed.

\section{Method}

2.1. Quantifying Early Yield Responses to FVM Treatments. Based on a meta-analytical approach, the analysis consisted of 4 sequential steps. Firstly, electronic databases were systematically searched for relevant publications using various keywords and phrases (e.g., combinations and permutations of the following terms: vegetation management treatments; black spruce, plantations; mechanical, chemical and biological release; brushing; herbicide, Vision; Roundup; glyphosate; Canadian Boreal and Great Lakes-St. Lawrence Forest Regions). These databases consisted of (1) SilverPlatter WebSPIRS (Ovid Technologies Inc., USA) which included Agricola, Biological Abstracts, CAB Abstracts, and TreeCD, (2) NRCan Forestry Library Catalogue (Natural Resources Canada), and (3) Science Direct Database and Scopus (Elsevier Science B.V.). Furthermore, the World Wide Web was similarly searched using Google Web Search and Google
Scholar (Google Inc., CA, USA). Secondly, the identified studies were assessed for their specific applicability in terms of locality (Great Lakes-St. Lawrence, and/or Boreal Forest Regions of Canada), stand-type (upland black spruce), treatments (mechanical, chemical, or biological), yield parameters assessed (basal stem diameter, total stem height, total stem volume, and survival), and publication date $(<2011)$. Thirdly, a subset of applicable studies was selected and their results summarized via the calculation of the grand mean effect size (response ratio) and associated 95\% confidence intervals for each yield variate (Table 1). The responses associated with the maximum dosage of a specific chemical treatment (e.g., glyphosate, hexazinone, sulfonylurea, combination of 2,4-D, mecoprop, and dicamba) or the maximum removal for a specific mechanical treatment (e.g., brushing, clipping, extraction) were used. Fourthly, the linear association between effect size and the individual experimental factors, that is, number of annual sequential treatments $\left(T_{N}\right)$, initial year of treatment application relative to the year of seedling establishment $\left(T_{I}(\mathrm{yr})\right)$, and length of the observation period relative to the year of seedling establishment $\left(T_{L}(\mathrm{yr})\right)$, was examined through graphical and correlation analyses.

Computational formulae based on a meta-analytic approach were used throughout (Hedges and Olkin [31]; Hedges et al. [32]). Specifically, the grand mean response ratio $\left(\bar{L}_{j}^{*}\right)$ of the $j$ th yield variate ( $j=1$ (basal diameter), 2 (total height), 3 (stem volume), and 4 (survival)) was calculated using the mean logarithmic response ratio of the $j$ th yield variate within the $k$ th experiment $\left(\bar{L}_{j(k)}\right)$ along with the reciprocal of the total unconditional variance estimate of $L_{j(k)}$ $\left(w_{j(k)}^{*}\right)$, according to $(1)$.

$$
\bar{L}_{j}^{*}=\operatorname{EXP}\left[\frac{\sum_{k=1}^{n_{j(k)}} w_{j(k)}^{*} \cdot \bar{L}_{j(k)}}{\sum_{k=1}^{n_{j(k)}} w_{j(k)}^{*}}\right],
$$

where

$$
\begin{gathered}
\bar{L}_{j(k)}=\frac{\sum_{i=1}^{n_{j(k)}} L_{j k(i)}}{n_{j(k)}} \text { where } L_{j k(i)}=\log _{e}\left(R_{j k(i)}\right), R_{j k(i)}=100 \cdot\left(\frac{\bar{T}_{j k(i)}-\bar{C}_{j k}}{\bar{C}_{j k}}\right), \\
w_{j(k)}^{*}=\left(v_{j(k)}+\hat{\sigma}_{j}^{2}\right), \quad \text { where }\left\{\begin{array}{l}
\hat{\sigma}_{j}^{2}=\frac{\left[\sum_{k=1}^{n_{j(k)}} w_{j(k)}\left(L_{j(k)}\right)^{2}-\left(\sum_{k=1}^{n_{j(k)}} w_{j(k)} L_{j(k)}\right)^{2} / \sum_{k=1}^{n_{j(k)}} w_{j(k)}\right]-\left(n_{j(k)}-1\right)}{\sum_{k=1}^{n_{j(k)}} w_{j(k)}-\sum_{k=1}^{n_{j(k)}} w_{j(k)}^{2} / \sum_{k=1}^{n_{j(k)}} w_{j(k)}}, \\
v_{j(k)}=\frac{\sum_{i=1}^{n_{j(k)}}\left(L_{j k(i)}-\bar{L}_{j(k)}\right)^{2}}{n_{j(k)}-1},
\end{array}\right.
\end{gathered}
$$

where $L_{j k(i)}$ and $R_{j k(i)}$ are the logarithmic $\left(\log _{e}(\%)\right)$ and arithmetic (\%) relative response of the $j$ th yield variate within the $k$ th experiment associated with the $i$ th experimental factor set (time of treatment, number of treatments applied, and type of treatment), respectively, $n_{j(k)}$ is the total number of response ratios observed for the $j$ th yield variate within the $k$ th experiment, $\bar{T}_{j k(i)}$ is the mean value of the $j$ th yield variate within the treated plots within the $k$ th experiment associated with the $i$ th experimental factor set, $\bar{C}_{j k}$ is the mean value of the $j$ th yield variate within the untreated 
TABLE 1: Relative yield responses and associated experimental details ordered by number of sequential treatments $\left(T_{N}\right)$, initial year of treatment application relative to the year of seedling establishment $\left(T_{I}(\mathrm{yr})\right)$; and length of the observation period relative to the year of seedling establishment $\left(T_{L}(\mathrm{yr})\right)$.

\begin{tabular}{cccccccc}
\hline$T_{N}^{\mathrm{a}}$ & $T_{I}^{\mathrm{a}}$ & $T_{L}^{\mathrm{a}}$ & \multicolumn{5}{c}{ Relative response $^{\mathrm{b}}$} \\
$(n)$ & $(\mathrm{yr})$ & $(\mathrm{yr})$ & $R_{D}$ & $R_{H}$ & $R_{V}$ & $R_{S}$ & Source and treatment details \\
& & & $(\%)$ & $(\%)$ & $(\%)$ & $(\%)$ & \\
\hline
\end{tabular}

Tables 1 and 2 and Figures 1, 4(b), and 6(b) as reported by Pitt et al. [18]; mean res-

$\begin{array}{lll}-1 & 4 & 73\end{array}$

43

339

10

ponses based on bareroot and container stock-types combined results; treatment = hexazinone (Velpar L) at $4 \mathrm{~kg}$ ai/ha (liquid formulation); effectiveness = reduction of $20 \%$ and $1 \%$ in herbaceous and woody vegetation cover, respectively, relative to untreated control plots, at time of last remeasurement.

Tables 1 and 2 and Figures 1(a,b) and 4(b,d) as reported by Reynolds and Roden [19]; mean responses based on spring and fall combined results; treatment = hexazinone (Velpar L) at $2 \mathrm{~kg}$ ai/ha (liquid formulation); effectiveness = reduction of $44 \%$ in red raspberry (Rubus idaeus L. var. strigosus (Michx.) Maxim.) (major competitor) cover, relative to untreated control plots, at time of last remeasurement.

Tables 1 and 2 and Figures 1(a,b), and 4(b,d) as reported by Reynolds and Roden [19]; mean responses based on spring and fall combined results; treatment = hexazinone (PRONONE $10 \mathrm{G})$ at $2 \mathrm{~kg}$ ai/ha (granular formulation); effectiveness = reduction of $38 \%$ in red raspberry (major competitor) cover, relative to untreated control plots, at time of last remeasurement.

Tables 1 and 2 and Figures 1(a,b) as reported by Reynolds and Roden [20]; mean responses based on spring and fall combined results; treatment $=$ sulfonylurea (Metsulfuron (ESCORT)) at $72 \mathrm{~g}$ ai/ha (liquid formulation); effectiveness = reduction of $47 \%$ in red raspberry (major competitor) cover, relative to untreated control plots, at time of last remeasurement.

Tables 2 and 3 as reported by Wood and von Althen [21]; mean responses based on bareroot and container stock-types combined results; treatment $=$ glyphosate (Roundup) at $2 \mathrm{~kg}$ ai/ha (liquid formulation); effectiveness = reductions of $20 \%$ and $25 \%$ in herbaceous and woody vegetation cover, respectively, relative to the untreated control plots, at time of last remeasurement.

Tables 1 and 2 and Figures 2(b,d) as reported by Reynolds and Roden [19]; mean responses based on spring and fall combined results; treatment $=$ hexazinone (Velpar L) at $2 \mathrm{~kg}$ ai/ha (liquid formulation); effectiveness = reduction of $44 \%$ in red raspberry (major competitor) cover, relative to untreated control plots, at time of last remeasurement.

Tables 1 and 2 and Figures 2(a,c) as reported by Reynolds and Roden [19]; mean responses based on spring and fall combined results; treatment $=$ hexazinone (PRONONE $10 \mathrm{G}$ ) at $2 \mathrm{~kg}$ ai $/$ ha (granular formulation); effectiveness = reduction of $38 \%$ in red raspberry (major competitor) cover, relative to untreated control plots, at time of last remeasurement.

Tables 1 and 2 and Figures 2(a,b) as reported by Reynolds and Roden [20]; treatment $=$ sulfonylurea (Sulfometuron $($ OUST) at $300 \mathrm{~g}$ ai/ha (liquid formulation); effectiveness $=$ reduction of $57 \%$ in red raspberry (major competitor) cover, relative to untreated control plots, at time of last remeasurement.

Tables 1 and 2 and Figure 1(a) as reported by Reynolds and Roden [20]; treatment = sulfonylurea (Metsulfuron (ESCORT) at $72 \mathrm{~g}$ ai/ha (liquid formulation); effectiveness $=$ reduction of $47 \%$ in red raspberry (major competitor) cover, relative to untreated control plots, at time of last remeasurement.

Table 1 as reported by Sutherland et al. [22] and Figure 1(d) as reported by Sutherland and Foreman [23]; treatment = hexazinone (Velpar L) at $3.1 \mathrm{~kg}$ ai $/ \mathrm{ha}$ (liquid formulation); effectiveness = initial reduction of competing vegetation at time of treatment; however, based on a vegetation index metric (height $\times$ cover), competition (red raspberry and trembling aspen (Populus tremuloides Michx.) increased $40 \%$, relative to the untreated control plots, at the time of last remeasurement. 
TABle 1: Continued.

\begin{tabular}{|c|c|c|c|c|c|c|c|}
\hline$T_{N}^{\mathrm{a}}$ & $T_{I}^{\mathrm{a}}$ & $T_{L}^{\mathrm{a}}$ & & lative & spons & & \\
\hline$(n)$ & $(\mathrm{yr})$ & $(\mathrm{yr})$ & $\begin{array}{c}R_{D} \\
(\%)\end{array}$ & $\begin{array}{c}R_{H} \\
(\%)\end{array}$ & $\begin{array}{c}R_{V} \\
(\%)\end{array}$ & $\begin{array}{c}R_{S} \\
(\%)\end{array}$ & Source and treatment details \\
\hline 1 & 0 & 5 & 26 & 19 & 109 & -9 & $\begin{array}{l}\text { Tables } 1,2,3 \text {, and } 4 \text { as reported by Jobidon et al. [24]; results for chemical } \\
\text { treatment at the Flynn experimental site; treatment = glyphosate (Vision) at } \\
1.5 \mathrm{~kg} \text { ai/ha (liquid formulation); untreated control plots dominated by red } \\
\text { raspberry ( } 63-75 \% \text { cover) at time of establishment. }\end{array}$ \\
\hline 1 & 0 & 5 & 42 & 27 & 204 & -4 & $\begin{array}{l}\text { Tables } 1,2,3 \text {, and } 4 \text { as reported by Jobidon et al. [24]: results for manual treatment } \\
\text { at the Flynn experimental site; treatment = physical removal via hedge clipper; } \\
\text { untreated control plots dominated by red raspberry ( } 63-75 \% \text { cover) at time of } \\
\text { establishment. }\end{array}$ \\
\hline
\end{tabular}

Tables 1, 2, 3, and 4 as presented Jobidon et al. [24]; results for chemical treatment at the Joncas experimental site; treatment $=$ glyphosate $($ Vision $)$ at $1.6 \mathrm{~kg}$ ai $/ \mathrm{ha}$

\begin{tabular}{|c|c|c|c|c|c|c|c|}
\hline 1 & 0 & 5 & 27 & 13 & 93 & 0 & $\begin{array}{l}\text { (liquid formulation); untreated control plots dominated by red raspberry ( } 2 \\
\text { cover) at time of establishment. }\end{array}$ \\
\hline 1 & 0 & 5 & 24 & 14 & 86 & 3 & $\begin{array}{l}\text { Tables } 1,2,3 \text {, and } 4 \text { as reported by Jobidon et al. [ } 24] \text { : results for manual trea } \\
\text { at the Joncas experimental site; treatment }=\text { physical removal via machete; un } \\
\text { control plots dominated by red raspberry }(24-45 \% \text { cover }) \text { at time of establish }\end{array}$ \\
\hline 1 & 0 & 5 & 45 & 20 & 104 & 2 & $\begin{array}{l}\text { Tables } 1,2,3 \text {, and } 4 \text { as reported by Jobidon et al. [24]; results for chemical } \\
\text { treatment at the Pilote experimental site; treatment = glyphosate (Vision) at } \\
1.6 \mathrm{~kg} \text { ai/ha (liquid formulation); untreated control plots dominated by red } \\
\text { raspberry ( } 71-79 \% \text { cover) at time of establishment. }\end{array}$ \\
\hline
\end{tabular}

Tables 1, 2, 3, and 4 as reported by Jobidon et al. [24]: results for manual treatment at the Pilote experimental site; treatment = physical removal via brush cutter;

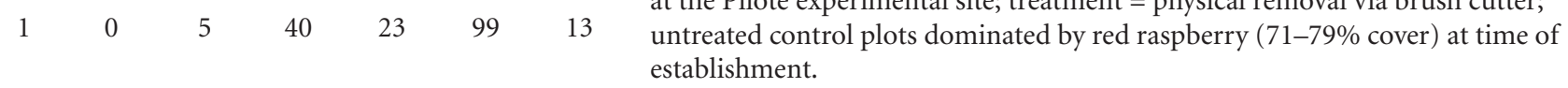

Tables 2 and 3 as reported by Wood and von Althen [21]; mean responses based on bareroot and container stock-types combined results; treatment $=$ glyphosate
$\begin{array}{lllllll}1 & 0 & 5 & 67 & 41 & - & 12\end{array}$
(Roundup) at $2 \mathrm{~kg}$ ai/ha (liquid formulation); effectiveness = reductions of $10 \%$ and $42.5 \%$ in herbaceous and woody vegetation cover, respectively, relative to untreated control plots, at time of last remeasurement.

Table 2 and Figures 1, 4(a), and 6(a) as reported by Pitt et al. [18]; mean responses based on bareroot and container stock-types combined results; treatment =

$\begin{array}{lllllll}1 & 0 & 5 & 68 & 38 & 273 \quad 5 \quad \begin{array}{l}\text { hexazinone (Velpar L) at } 4 \mathrm{~kg} \text { ai/ha (liquid formulation); effectiveness = reduction } \\ \text { of } 20 \% \text { and } 1 \% \text { in herbaceous and woody vegetation cover, respectively, relative to } \\ \text { untreated control plots, at time of last remeasurement. }\end{array}\end{array}$

Table 1 and Figure 2 as reported by Wagner et al. [25]; treatment = glyphosate (Vision) at $4 \mathrm{~kg}$ ai/ha (liquid formulation); effectiveness = reduction of $10 \%$ in herbaceous vegetation cover relative to the untreated control plots at the time of last remeasurement (n., nil competition from woody species).

Table 2 as reported by Jobidon and Charette [26]; results for Squatec experimental site; treatment $=$ manual removable via pulling of all vegetation within $60 \mathrm{~cm}$ of subject trees; principal competitor species were removed (red raspberry and fireweed).

Table 4 as reported by Jobidon and Charette [26]; results for Lake Anna experimental site; treatment $=$ mechanized manual removable via brush cutter of all vegetation within $60 \mathrm{~cm}$ of subject trees; principal competitor species were removed (shade intolerant deciduous trees).

Table 4 as reported by Jobidon and Charette [26]; results for Lake Anna; treatment = manual removable via pulling of all competing vegetation; principal competitor species were removed (shade intolerant deciduous trees). 
TABle 1: Continued.

\begin{tabular}{|c|c|c|c|c|c|c|c|}
\hline \multirow{2}{*}{$\begin{array}{l}T_{N}^{\mathrm{a}} \\
(n)\end{array}$} & \multirow{2}{*}{$\begin{array}{c}T_{I}^{\mathrm{a}} \\
(\mathrm{yr})\end{array}$} & \multirow{2}{*}{$\begin{array}{c}T_{L}^{\mathrm{a}} \\
(\mathrm{yr})\end{array}$} & \multicolumn{4}{|c|}{ Relative response $^{\mathrm{b}}$} & \multirow[b]{2}{*}{ Source and treatment details } \\
\hline & & & $\begin{array}{c}R_{D} \\
(\%)\end{array}$ & $\begin{array}{c}R_{H} \\
(\%)\end{array}$ & $\begin{array}{l}R_{V} \\
(\%)\end{array}$ & $\begin{array}{c}R_{S} \\
(\%)\end{array}$ & \\
\hline 1 & 0 & 11 & 78 & 18 & - & -10 & $\begin{array}{l}\text { Figures } 3,5 \text {, and } 7 \text { as reported by Wood and Mitchell [27]; results for Bragg } \\
\text { experiment; mean responses based on bareroot and container stock-types } \\
\text { combined results; treatment = glyphosate (Roundup) at } 2.5 \mathrm{~kg} \text { ai/ha (liquid } \\
\text { formulation); effectiveness = reductions of } 97 \% \text { in competing vegetation } \\
\text { (principally trembling aspen), relative to the untreated control plots, at time of last } \\
\text { remeasurement. }\end{array}$ \\
\hline
\end{tabular}

Figure 1 as reported by Robinson et al. [28]; mean response of brush control treatment relative to untreated control plots; treatment = glyphosate (Roundup) at $2.2 \mathrm{~kg}$ acid equivalent/ha (liquid formulation) on bladed scarified sites; effectiveness: at the time of the $15 \mathrm{yr}$ post-treatment assessment, the treatment had eliminated the noncrop hardwood species.

Tables 2 and 3 as reported by Wood and von Althen [21]; mean responses based on bareroot and container stock-types combined results; treatment = glyphosate

$\begin{array}{lllllll}1 & 1 & 5 & 31 & 10 & - & -11\end{array}$

(Roundup) at $2 \mathrm{~kg}$ ai/ha (liquid formulation); effectiveness = reductions of $5 \%$ and $35 \%$ in herbaceous and woody vegetation cover, respectively, relative to untreated control plots, at time of last remeasurement.

Figures 3, 5, and 7 as reported by Wood and Mitchell [27]; results for Bragg experiment; mean responses based on bareroot and container stock-types and spring and summer seasonal results combined; treatment = glyphosate (Roundup) at $2.5 \mathrm{~kg}$ ai $/$ ha (liquid formulation); effectiveness = reductions of $98 \%$ in competing vegetation (principally trembling aspen), relative to the untreated control plots, at time of last remeasurement.

Textual description and Figure 1 as reported in Pitt et al. [29] for Corrigal experimental site; annual directed foliar application of 1.58 or $2 \%$ liquid solution of glyphosate (Vision); effectiveness: at the time of the $10 \mathrm{yr}$ remeasurement the average of all treatments had reduced the cover of deciduous woody tree species to less than $10 \%$, tall shrub species to $2 \%$, and low shrub species to $20 \%$.

Figures 3, 5, and 7 as reported by Wood and Mitchell [27]; results for Kenogaming experiment; mean responses based on bareroot and container stock-types and spring and summer seasonal results combined; treatment = glyphosate (Roundup) at $2.14 \mathrm{~kg}$ ai/ha (liquid formulation); effectiveness = reductions of $76 \%$ in competing vegetation (principally trembling aspen), relative to the untreated control plots, at time of last remeasurement.

Figures 3, 5, and 7 as reported by Wood and Mitchell [27]; results for Lampugh experiment; mean responses based on bareroot and container stock-types and spring and summer seasonal results combined; treatment = glyphosate (Roundup) at $2.14 \mathrm{~kg}$ ai $/$ ha (liquid formulation); effectiveness = reductions of $94 \%$ in competing vegetation (principally trembling aspen), relative to the untreated control plots, at time of last remeasurement.

Textual description and Figure 1 as reported in Pitt et al. [29] for Hele experimental site; treatment $=$ glyphosate $($ Vision $)$ at $1.7 \mathrm{~kg}$ ai/ha (liquid formulation); effectiveness: at the time of the $10 \mathrm{yr}$ remeasurement the average of all treatments had reduced the cover of deciduous woody tree species to less than $10 \%$, tall shrub species to $2 \%$, and low shrub species to $20 \%$.

Table 1 and Figure 2 as reported by Wagner et al. [25]; treatment = glyphosate (Vision) at $4 \mathrm{~kg}$ ai/ha (liquid formulation); effectiveness = reduction of $20 \%$ in herbaceous vegetation cover, relative to the untreated control plots, at the time of last remeasurement (n., nil competition from woody species).

Table 1 and Figure 2 as reported by Wagner et al. [25]; treatment = glyphosate (Vision) at $4 \mathrm{~kg}$ ai/ha (liquid formulation); effectiveness = reduction of $21 \%$ in herbaceous vegetation cover, relative to the untreated control plots, at the time of last remeasurement $(n$. , nil competition from woody species). 
Table 1: Continued.

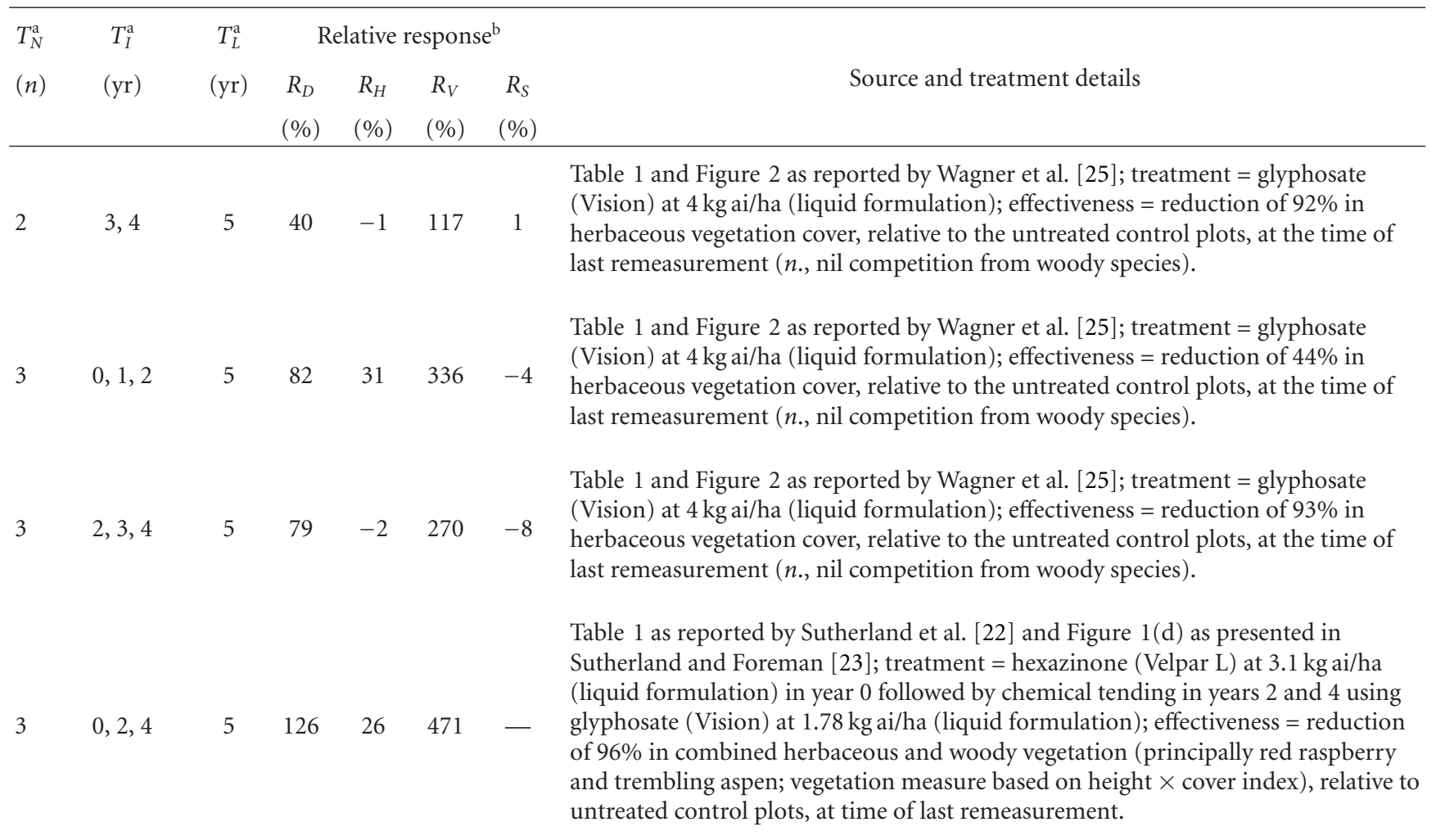

Table 1 and Figure 2 as reported by Wagner et al. [25]; treatment = glyphosate (Vision) at $4 \mathrm{~kg}$ ai/ha (liquid formulation); effectiveness = reduction of $57 \%$ in herbaceous vegetation cover, relative to the untreated control plots, at the time of last remeasurement ( $n$., nil competition from woody species).

Table 1 and Figure 2 as reported by Wagner et al. [25]; treatment = glyphosate (Vision) at $4 \mathrm{~kg}$ ai/ha (liquid formulation); effectiveness = reduction of $94 \%$ in last remeasurement ( $n$., nil competition from woody species).

Figures $13,14,15$, and 16 as reported by Robinson et al. [28]; results for the scarified but unfertilized plots only; treatment $=$ glyphosate $($ Vision $)$ at $2 \mathrm{~kg}$ ai/ha

$\begin{array}{lllllll}4 & -1,0,1,2 & 14 & 93 & 43 & 125 & 12\end{array}$
(liquid formulation); effectiveness = approximate reduction of $100 \%$ in herbaceous and woody vegetation cover, relative to the untreated control plots, 3 years post-planting.

Tables 2 and 3 as reported by Wood and von Althen [21]; mean responses based on bareroot and container stock-types results combined; treatment = annual application of glyphosate (Roundup) at $2 \mathrm{~kg}$ ai/ha (liquid formulation); effectiveness $=$ reductions of $90 \%$ and $100 \%$ in herbaceous and woody vegetation cover, respectively, relative to the untreated control plots, at time of last remeasurement.

Table 1 and Figure 2 as reported by Wagner et al. [25]; treatment = glyphosate (Vision) at $4 \mathrm{~kg}$ ai/ha (liquid formulation); effectiveness = reduction of $96 \%$ in $5 \quad 0,1,2,3,4 \quad 5 \quad 108 \quad 22 \quad 420 \quad 12$ 12 herbaceous vegetation cover, relative to the untreated control plots, at the time of last remeasurement ( $n$., nil competition from woody species).

Textual description and Figure 1 as reported in Pitt et al. [29] for Corrigal experimental site; annual directed foliar application of 1.58 or $2 \%$ liquid solution of glyphosate (Vision); effectiveness: at the time of the $10 \mathrm{yr}$ remeasurement the average of all treatments had reduced the cover of deciduous woody tree species to less than $10 \%$, tall shrub species to $8 \%$, and low shrub species to $20 \%$. 
TABLE 1: Continued.

\begin{tabular}{|c|c|c|c|c|c|c|c|}
\hline$T_{N}^{\mathrm{a}}$ & $T_{I}^{\mathrm{a}}$ & $T_{L}^{\mathrm{a}}$ & & ative & espon & & \\
\hline$(n)$ & $(\mathrm{yr})$ & (yr) & $\begin{array}{c}R_{D} \\
(\%)\end{array}$ & $\begin{array}{c}R_{H} \\
(\%)\end{array}$ & $\begin{array}{c}R_{V} \\
(\%)\end{array}$ & $\begin{array}{c}R_{S} \\
(\%) \\
\end{array}$ & Source and treatment details \\
\hline 5 & $3,4,5,6,7$ & 10 & 87 & 8 & 126 & - & $\begin{array}{l}\text { Textual description and Figure } 1 \text { as reported in Pitt et al. [29] for Hele experimental } \\
\text { site; annual directed foliar application of } 1.58 \text { or } 2 \% \text { liquid solution of glyphosate } \\
\text { (Vision); effectiveness: at the time of the } 10 \mathrm{yr} \text { remeasurement the average of all } \\
\text { treatments had reduced the cover of deciduous woody tree species to less than } 10 \% \text {, } \\
\text { tall shrub species to } 2 \% \text {, and low shrub species to } 20 \% \text {. }\end{array}$ \\
\hline 6 & $-1,0,1,2,3,4$ & 5 & 221 & 95 & - & 22 & $\begin{array}{l}\text { Tables } 2 \text { and } 3 \text { as reported by Wood and von Althen [21]; mean responses based on } \\
\text { bareroot and container stock-types results combined; treatment = annual } \\
\text { application glyphosate (Roundup) at } 2 \mathrm{~kg} \text { ai/ha (liquid formulation) including } \\
\text { pre-planting treatment; effectiveness = reductions of } 90 \% \text { and } 100 \% \text { in herbaceous } \\
\text { and woody vegetation cover, respectively, relative to the untreated control plots, at } \\
\text { time of last remeasurement. }\end{array}$ \\
\hline
\end{tabular}

Note, all selected studies were located within the Great Lakes - St. Lawrence or Boreal Forest Regions [30].

a Number of sequential treatments $\left(T_{N}\right)$; Initial year of treatment application relative to the year of seedling establishment $(-1=$ year before planting (e.g., chemical site preparation); 0 = year of seedling establishment; $1,2, \ldots, 7$ years after seedling establishment, resp.; $\left.\left(T_{I}\right)\right)$; and Length of the observation period relative to the year of seedling establishment $\left(T_{L}\right)$.

${ }^{\mathrm{b}} R_{k}=100 \cdot\left(\bar{T}_{k}-\bar{C}_{k}\right) / \bar{C}_{k}$ where $R_{j}$ is the relative response (\%) of the $k$ th yield variate ( $D=$ basal stem diameter; $H=$ total stem height; $V=$ total stem volume; and $S=$ survival), $\bar{T}_{k}$ is the mean value of the $k$ th yield variate within the treated population, and $\bar{C}_{k}$ is the mean value of the $k$ th yield variate within the untreated control population.

plots within the $k$ th experiment, $v_{j(k)}$ is variation due to sampling of the $j$ th yield variate within the $k$ th experiment, $w_{j(k)}$ is equal to the inverse of $v_{j(k)}$, and $\hat{\sigma}_{j}^{2}$ is the amongstudy variation associated with the $j$ th yield variate. The $95 \%$ confidence intervals for $\bar{L}_{j}^{*}$ were first calculated according to (3) and then reexpressed in arithmetic terms:

$$
\begin{array}{r}
\bar{L}_{j}^{*}-z_{\alpha / 2} \cdot \operatorname{SE}\left(\bar{L}_{j}^{*}\right) \leq \mu \leq \bar{L}_{j}^{*}+z_{\alpha / 2} \cdot \operatorname{SE}\left(\bar{L}_{j}^{*}\right), \\
\text { where } \operatorname{SE}\left(\bar{L}_{j}^{*}\right)=\sqrt{\frac{1}{\sum_{\mathrm{k}=1}^{n_{j(k)}} w_{j(k)}^{*}}},
\end{array}
$$

where $z_{\alpha / 2}$ is the $97.5 \%$ point of the standard normal distribution, and $\operatorname{SE}\left(\bar{L}_{j}^{*}\right)$ is the standard error of the weighted mean associated with the $j$ th yield variate. Note that the variance in response among treatments within an individual experiment was used as a surrogate measure of sample variation $\left(v_{j(k)}\right)$ given the lack of studies reporting treatmentspecific sample variation. Consequently, the resultant mean values and the associated confidence limits represent the average collective response of black spruce over a range of FVM treatments.

\subsection{Modeling Long-Term Yield Responses. Responses to FVM} treatments were assumed to follow a Type I growth response pattern (sensu [33]): a temporary increase in growth rate that advances the stage of stand development but does not change the inherent productivity of a site. Consequently, an approach analogous to the technique used to account for genetic worth effects in growth and yield projections was employed (i.e., genetic worth effect is quantified as the temporary and instantaneous increase in mean dominant height growth at the specified selection age which is thereafter proportionally discounted until rotation age [34]). Thus the FVM treatment effect was defined as the temporary and instantaneous increase in mean dominant height growth $\left(V_{E} ; \%\right)$ at a specified effect age $\left(V_{A} ; y r\right)$ which thereafter proportionally declined until rotation age. Mathematically, the following script describes the computation:

$$
\begin{aligned}
& \text { If } V_{E}>0 \text {, then for } t=V_{A}, \\
& \hat{H}_{d(t)}^{\prime}=\hat{H}_{d(t)}+\left(\frac{V_{E}}{100}\right) \hat{H}_{d(t)}, \\
& \text { otherwise when } t>V_{A}, \\
& \hat{H}_{d(t)}^{\prime}=\hat{H}_{d(t)}+\left(\frac{V_{E}}{100}-\left(\left(\frac{V_{E} / 100}{R_{A}-V_{A}}\right)\left(t-V_{A}\right)\right)\right) \hat{H}_{d(t)},
\end{aligned}
$$

where $\hat{H}_{d(t)}$ is the dominant height $(\mathrm{m})$ at time $t$ as predicted by the site-based height-age function, $\hat{H}_{d(t)}^{\prime}$ is the treatment-adjusted dominant height $(\mathrm{m})$ at time $t$, and $R_{A}$ is the rotation age (yr). Furthermore, in order to account for the effect of FVM treatments on survival, the annual mortality rate during the pre-crown closure period within the untreated stand was adjusted according to the following computational script:

$$
\begin{aligned}
& \text { If } S_{E}>0 \text { then for } t<T_{\mathrm{CC}}, \\
& M_{(t)}=\hat{N}_{(t)}\left(1-\left(\frac{1.0}{1+S_{E} / 100 S_{A}}\right)\right),
\end{aligned}
$$

where $S_{E}$ is the grand mean survival response (\%) occurring at a specified effect age $\left(S_{A} ; \mathrm{yr}\right), T_{\mathrm{CC}}$ is the age of the untreated stand at crown closure, $\hat{N}_{(t)}$ is the model-based predicted density (stems/ha) at time $t$ within the control stand, and $M_{(t)}$ is the annual increase in the mortality rate (stems/ha/yr) at time $t$.

These modifications to the height and survival computations were then incorporated within the CROPLANNER decision-support model $[5,6]$. Briefly, CROPLANNER is the algorithmic analogue of the structural stand density management model (SSDMM) which was developed for black 
spruce and jack pine stand-types through the expansion of the dynamic stand density management diagram modelling framework. Structurally, the model consists of a number of functional and empirical quantitative relationships, which collectively represent the cumulative effect of various underlying competition processes on tree and stand yield parameters. The temporal dependency of these processes is governed by the intensity of competition and site quality as expressed by relative density index and site index, respectively. Hence, the site-specific mean dominant height-age function largely governs the rate of stand development. Thus embedding the anticipated Type I response pattern within this function was considered a logical approach to modeling the effects of FVM treatments on growth. For a complete analytical description of the approach used in the development and calibration of the modular-based SSDMMs, refer to $[5,6]$.

\section{Results}

3.1. Early Responses and Their Correlation to Experimental Variables. Results from 12 experiments were used in the calculation of the grand mean response ratios and associated 95\% confidence intervals. The author(s) of these studies were as follows: Wood and von Althen [21], Reynolds and Roden [19, 20], Wood and Mitchell [27], Jobidon and Charette [26], Jobidon et al. [24], Pitt et al. [18], Wagner et al. [25], Sutherland et al. [22], Sutherland and Foreman [23], Robinson et al. [28], Pitt et al. [29], and Fu et al. [35]. Experimentally, the studies differed in terms of the number of sequential treatments applied, initial year of treatment application relative to the year of seedling establishment, and length of the observation period relative to the year of seedling establishment: $\bar{T}_{N}=1.9(\min / \max =1 / 6), \bar{T}_{I}=0.4 \mathrm{yr}(-1 / 4)$, and $\bar{T}_{L}=$ $6.7 \mathrm{yr}(4 / 15)$. The mean percentage response for basal diameter, total height, stem volume, and survival across all experiments was, respectively, $66.9(\mathrm{~min} / \mathrm{max} / n=14.9 /$ 220.9/44), 29.3 (-1.6/96.0/43), 208.1 (68.6/470.7/25), and $2.5(-37.7 / 47.6 / 37)$. Table 1 summarizes the characteristics of the selected studies in terms of their experimental design, type and number of sequential treatments applied, time of initial treatment relative to seedling establishment, duration of response period, effectiveness of the treatments, and mean responses observed.

The mean effect size and associated 95\% confidence intervals for basal diameter, total height, stem volume, and survival were, respectively, 54.7\% (95\% confidence limits (lower/upper): 34.8/77.6), 27.3\% (15.7/40.0), 198.7\% (70.3/ $423.5)$, and $2.9 \%(-5.5 / 11.8)$. Hence, FVM treatments resulted in significant $(P \leq 0.05)$ early gains in mean tree size. Linear correlation analysis revealed the following significant $(P \leq 0.05)$ associations: $(1)$ mean effect size for diameter (product-moment correlation coefficient $(r)=0.74$ ) and volume $(r=0.48)$ increased with increasing $T_{N}$, and (2) mean effect size for height $(r=-0.53)$ and survival $(r=$ -0.38 ) decreased with increasing $T_{I}$. These results suggest that early and repeated FVM treatments will yield the largest gains in terms of mean tree size and survival.
3.2. Long-Term Effects on Yield Outcomes and Stand Operability Status. The lower and upper limits of the 95\% confidence interval for the mean percent gain in height growth $\left(V_{E}\right)$ and the corresponding mean effect age $\left(V_{A}\right)$, along with the mean percent gain in survival $\left(S_{E}\right)$ and the associated mean effect age $\left(S_{A}\right)$, were used as input to the modified CROPLANNER model. A conventional silvicultural regime applicable to the upland black spruce stand-type was simulated: planting 2100 seedlings per hectare on a scarified site was modeled over a 75-year rotation for a poor-medium quality site (site index $=14$ [36]), and a 50-year rotation for a goodexcellent (site index $=18$ [36]) quality site. The objective underlying the FVM treatment was to reduce the time to operability status as defined by site-specific piece-size and merchantable volume productivity thresholds: 15 stems $/ \mathrm{m}^{3}$ and $150 \mathrm{~m}^{3} /$ ha for the lower site quality, and $10 \mathrm{stems} / \mathrm{m}^{3}$ and $200 \mathrm{~m}^{3} /$ ha for the higher site quality. Three regimes were assessed on each site: (1) Regime 1 consisted of an untreated control stand in which the short-lived competitors (e.g., ericaceae plants, herbaceous forbs, shrubs, and small trees) were assumed to be eventually shaded out once crown closure status was achieved and hence the post-closure succession pattern followed that of monospecific plantation; (2) Regime 2 was subjected to an FVM treatment in which the response was assumed to follow the patterns described by the aforementioned scripts using the results from the meta-analysis; specifically, the (i) height growth increase was defined by the lower limit of the $95 \%$ confidence limit, that is, $V_{E}=$ $15.7 \%$, which took effect at the specified $V_{A}$ of $7 \mathrm{yr}$, and (ii) survival increase was defined by the mean value derived from all the studies $\left(S_{E}=2.9 \% ; S_{A}=7 \mathrm{yr}\right)$; (3) Regime 3, similar to Regime 2, was subjected to an FVM treatment in which the (i) height growth response was defined by the upper limit of the $95 \%$ confidence limit, $V_{E}=40.0 \%$, taking effect at the specified $V_{A}$ of $7 \mathrm{yr}$, and (ii) survival increase was defined by the mean value derived from the studies $\left(S_{E}=2.9 \% ; S_{A}=\right.$ $7 \mathrm{yr})$.

The resultant mean volume-density trajectories for each regime within the context of the CROPLANNER-based graphic are illustrated in Figures 1 and 2 for plantations situated on poor-medium and good-excellent site qualities, respectively. Although the graphics can be used to derive estimates of density, mean volume, total volume, quadratic mean diameter, basal area, and mean live crown ratio, for any age on a given trajectory via graphical interpolation, they are presented so that the general stand development implications of FVM treatments can be visualized and interpreted within the context of the widely used stand density management diagram. Contrasting the two diagrams reveals that the trajectories progressed through the size-density space at a greater rate on the good-excellent site than on the poormedium site, irrespectively of treatments. The divergent mean volume-density trajectories among the regimes during the pre-crown closure period (i.e., portion of the trajectories that are below the crown closure line) are indicative of the greater mortality rate arising from interspecific competition effects within the control stands. Similarly, this differential in survival rate is carried forward until rotation age as evident from the separation of the control and treated trajectories 


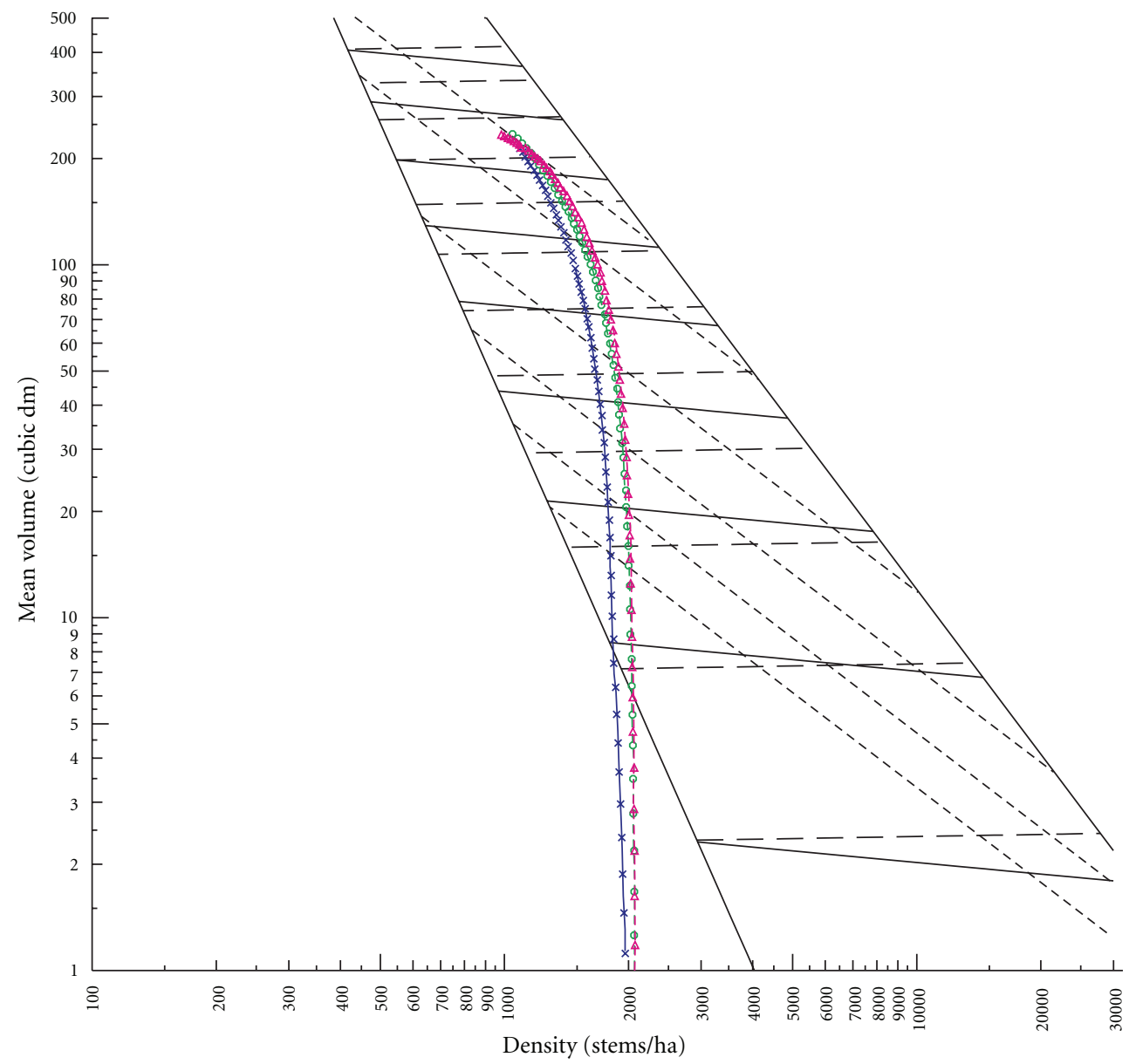

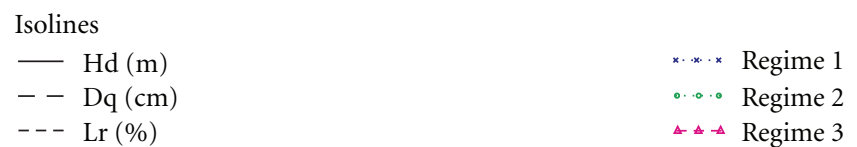

FIGURE 1: Seventy-five year temporal size-density trajectories for upland black spruce plantations situated on low-medium quality sites (site index = 14): Regime 1—no FVM treatment applied; Regime 2-FVM treatment with an expected effect of a 15.7\% height gain at age 7; and Regime 3-FVM applied with an expected effect of a 40.0\% height gain at age 7. Graphically, illustrating the (1) isolines for mean dominant height (Hd; 4-20 m by $2 \mathrm{~m}$ intervals), quadratic mean diameter (Dq; 4-26 cm by $2 \mathrm{~cm}$ intervals), and mean live crown ratio (Lr; 35, 40, 50, $\ldots, 80 \%$ ), and (2) crown closure line (lower boundary of the size-density space as delineated by the lower left diagonal solid line) and the self-thinning rule (upper boundary of the size-density space as delineated by the upper right diagonal solid line).

during the post-crown closure period. In accordance with the Type I response pattern assumed in the model, all three regimes approached equivalence in terms of their size-density trajectories and associated yield-based productivity indices at rotation, as inferred from the approximate convergence of the size-density trajectories. However, it was evident from the annual progression within the trajectories that the treated regimes experienced an acceleration in the rate of their development during the post-treatment period.

Figure 3 illustrates the predicted mean dominant height development with the FVM treatment effect incorporated. Based on the Type I response pattern, (1) height growth underwent an instantaneous acceleration at the specified effect age $(7 \mathrm{yr})$ which then declined for the remaining portion of the rotation, and (2) from the point of treatment until rotation age, the productivity as measured by site height was always greater within the treated stands than that within the untreated stands. This increase in the rate of stand development resulted in crown closure occurring approximately $5 \mathrm{yr}$ earlier within the treated stands, than within the control stands. Over the rotation, the effect of the increase in the rate of stand development and survival was to increase site occupancy and volumetric production, which translated into a substantial reduction in the time to operability status. Specifically, examining the temporal dynamics of the piece sizeage (Figure 4) and the merchantable volume-age (Figure 5) relationships derived from the modified CROPLANNER model, indicated that the operability thresholds for the treated and control regimes were attained at (1) ages 39 and 45 for the $15 \mathrm{stems} / \mathrm{m}^{3}$ piece size threshold, respectively, and 


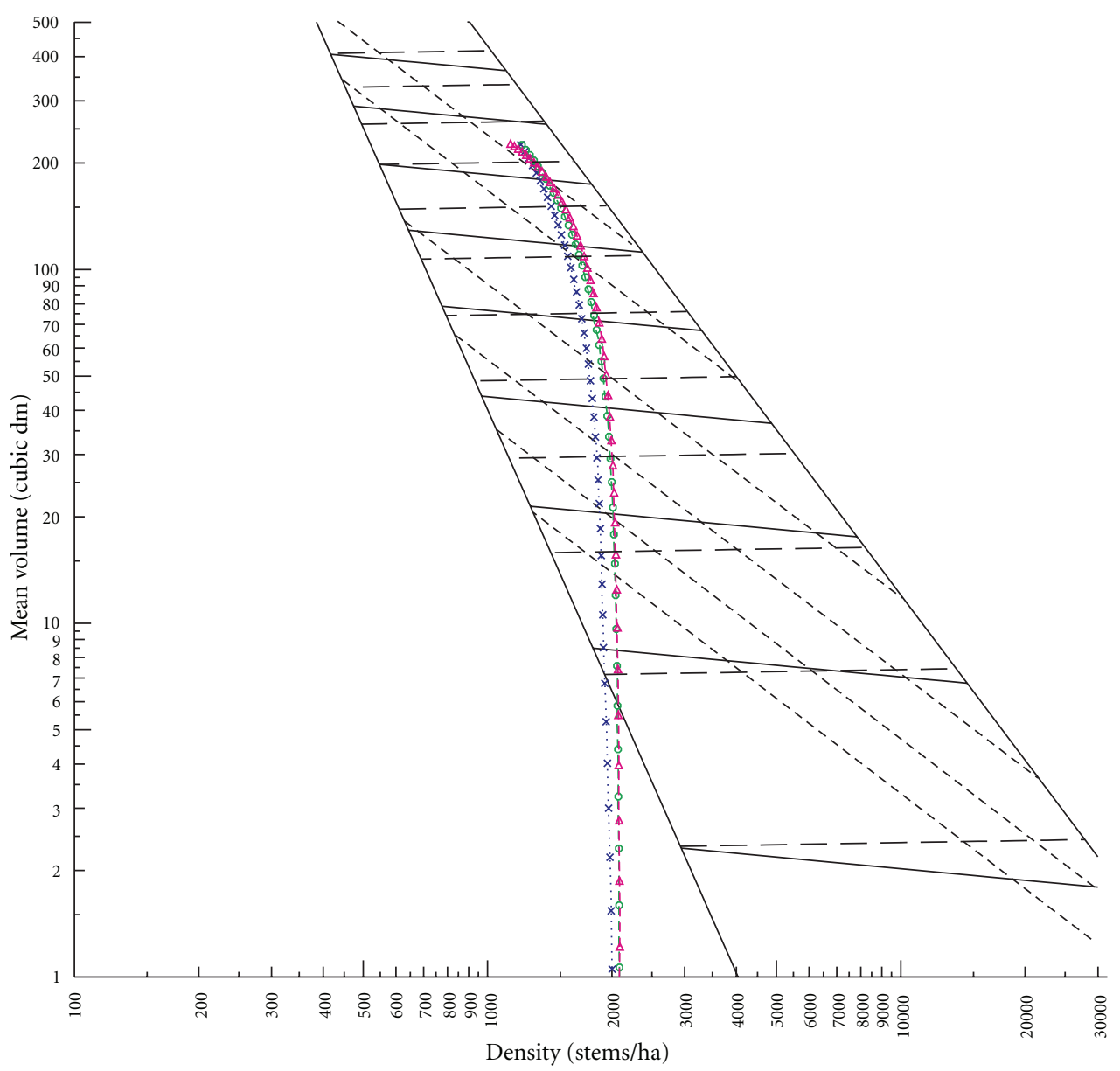

Isolines

\begin{tabular}{|c|c|}
\hline $\mathrm{Hd}(\mathrm{m})$ & ****x Regime 1 \\
\hline$-\mathrm{Dq}(\mathrm{cm})$ & $\cdots \cdots$ Regime 2 \\
\hline$--\operatorname{Lr}(\%)$ & $\Delta \star \Delta$ Regime 3 \\
\hline
\end{tabular}

FIGURE 2: Fifty-year temporal size-density trajectories for upland black spruce plantations situated on good-excellent quality sites (site index = 18): Regime 1: no FVM treatment applied; Regime 2: FVM treatment with an expected effect of a 15.7\% height gain at age 7; and Regime 3: FVM applied with an expected effect of a 40.0\% height gain at age 7. Graphical denotations are given in Figure 1.

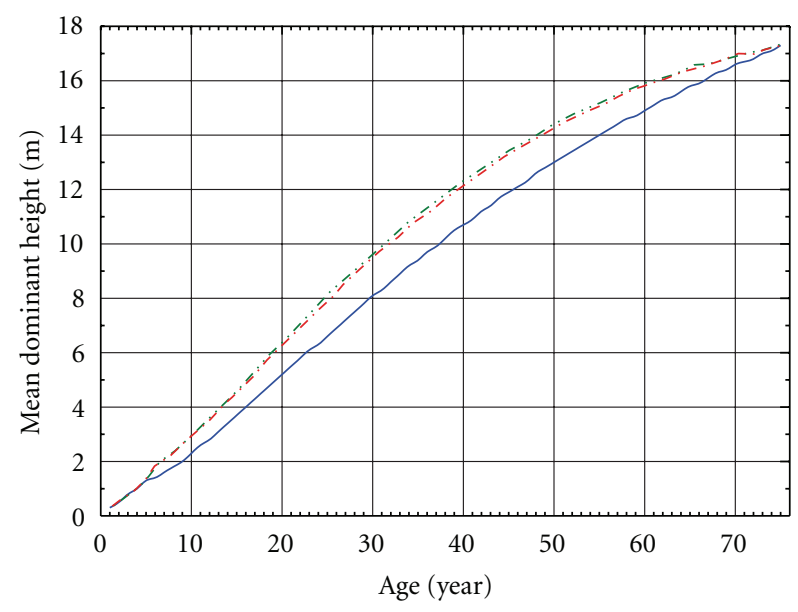

(a)

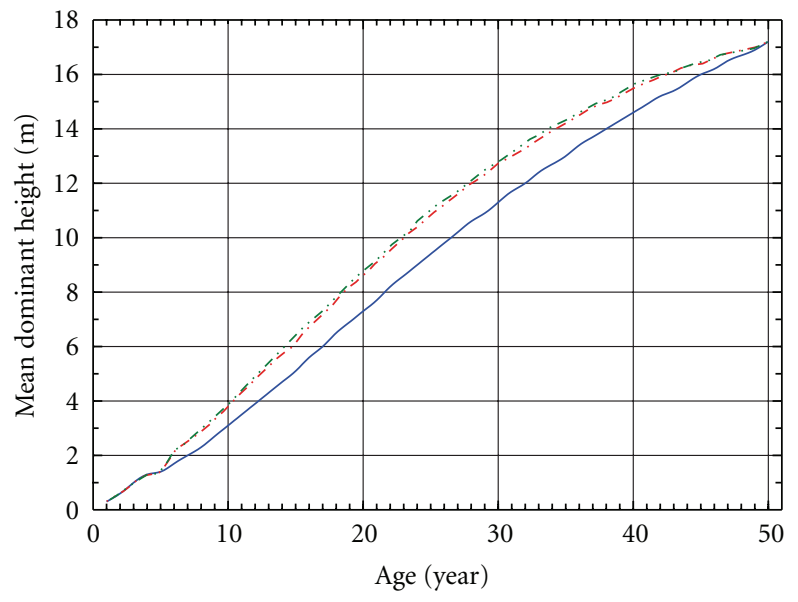

(b)

Figure 3: Type I response pattern as reflected in the mean dominant height-age relationship for poor-medium (a) and good-excellent (b) site qualities: Regime 1: no FVM treatment applied (solid line); Regime 2: FVM treatment with an expected effect of a $15.7 \%$ gain at age 7 (long-short dash line); and Regime 3: FVM applied with an expected effect of a 40.0\% gain at age 7 (long-short-short dash line). 


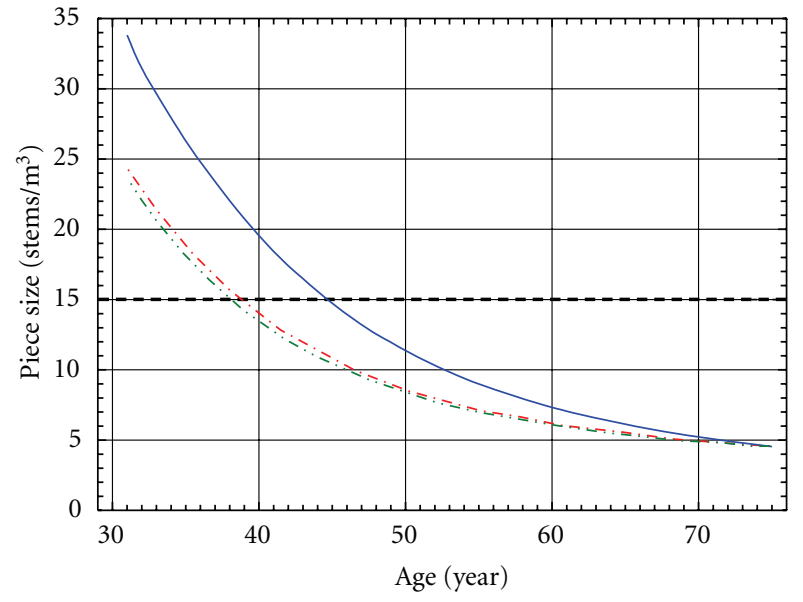

(a)

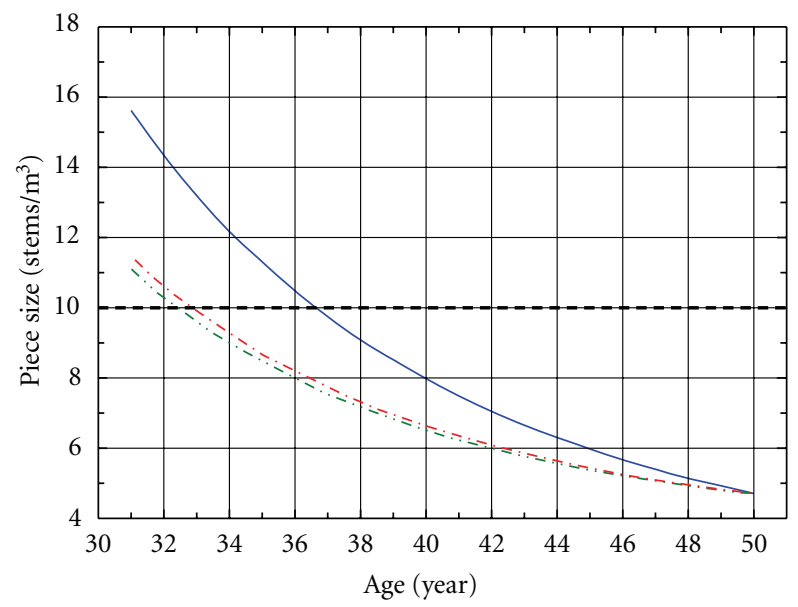

(b)

Figure 4: Type I response pattern as reflected in the piece size-age relationship for poor-medium (a) and good-excellent (b) site qualities. Regime denotations are given in Figure 3. Note that the intersection of the horizontal dotted line denoting the specified operability criterion with a production curve indicates the earliest age at which the piece size operability criterion is attained.

at ages 45 and 54 for the $150 \mathrm{~m}^{3} /$ ha merchantable volume thresholds, respectively, on the poor-medium quality site (Figures 4(a) and 5(a), resp.), and (2) ages 33 and 37 for the 10 stems $/ \mathrm{m}^{3}$ piece size threshold, respectively, and at ages 37 and 42 for the $200 \mathrm{~m}^{3}$ /ha merchantable volume thresholds, respectively, on the good-excellent quality site (Figures 4(b) and 5(b), resp.). Thus relative to the untreated control stands, the earliest time that the treated stands reached the specified piece size and merchantable volume thresholds was approximately $9 \mathrm{yr}$ less on the poor-medium site (earliest time at which both operability criteria were realized: $45 \mathrm{yr}$ for the treated stands versus $54 \mathrm{yr}$ for the control stand), and approximately $5 \mathrm{yr}$ less on the good-excellent site ( $37 \mathrm{yr}$ for the treated stands versus $42 \mathrm{yr}$ for the control stand). These operability improvements suggest that substantial reductions in economic rotation lengths are possible with the application of early and repeated FVM treatments.

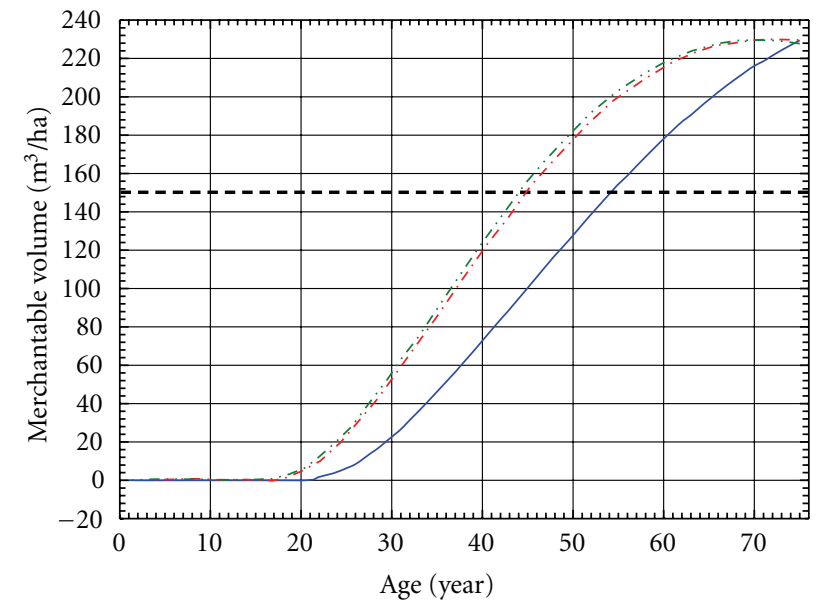

(a)

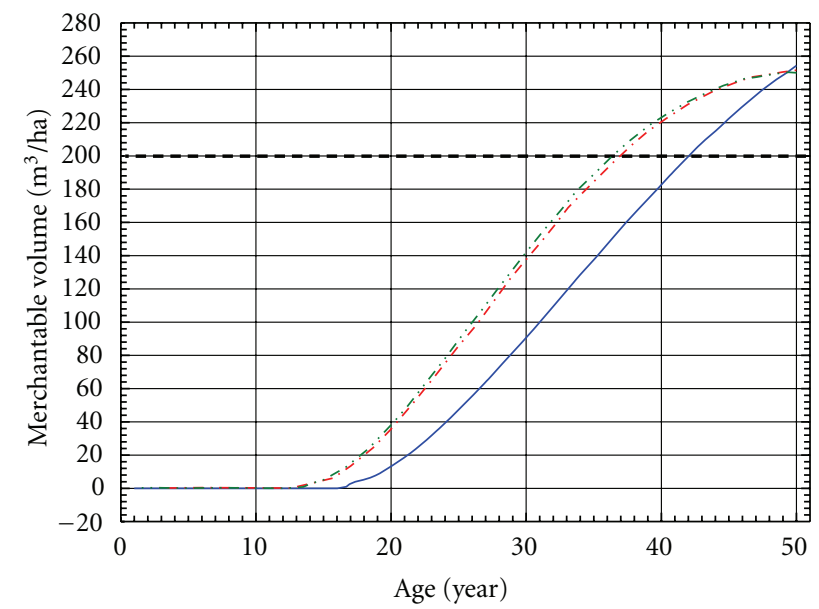

(b)

FIGURE 5: Type I response pattern as reflected in the merchantable volume-age relationship for poor-medium (a) and good-excellent (b) site qualities. Regime denotations are given in Figure 3. Note that the intersection of the horizontal dotted line denoting the specified operability criterion with a production curve indicates the earliest age at which the merchantable volume operability criterion is attained.

\section{Discussion}

Competition from interspecific herbaceous and woody competitors during the early stages of plantation development may involve a continuum ranging from a resource depletion to a preemption process (sensu [37]). The resource depletion process is a symmetrical relationship in which all species compete for belowground resources (e.g., all competitors acquire an equal share of the available nutrients and moisture on a per-unit size basis). Conversely, the resource preemption process is an asymmetrical relationship in which the largersized competitors acquire a greater size-proportional share of the aboveground resources than smaller-sized competitors (e.g., larger-sized competitors acquire a greater share of the solar-based resources than smaller-sized competitors on a per-unit size basis). FVM treatments are an effective method 
of minimizing the detrimental effects of these competition processes on the crop tree population via the selective elimination of interspecific competitors. However, the duration of the effect is dependent on the effectiveness of the FVM treatment applied in terms of reducing both the herbaceous and noncrop woody competitors. Based on a collective review of studies in the Pacific Northwest, Lake States, and Ontario, Wagner [38] suggested that removing interspecific woody competitors may only secure an increase in the order of $20-30 \%$ of early crop tree volume growth potential and hence achieving the remaining $70-80 \%$ will also require effective control of the herbaceous vegetation.

The results of this study indicated that relative to untreated control stands, mean basal diameter, total height, stem volume, and survival within treated stands, increased by $54.7 \%, 27.3 \%, 198.7 \%$, and 2.9\%, respectively. These responses correspond to the maximal treatment reported in the selected studies and consequently represent the best-case scenario, irrespective of the control mechanism employed. These empirical results are in accordance with the scientific consensus regarding the general effectiveness of FVM treatments on conifers $[8,39]$ : effective removable of competing vegetation results in initial increases in growth. The results also indicated that early and repeated treatments yielded the largest gains. The generalized responses are consistent with those reported in individual experiments which did not meet the selection criteria employed in this study. For example, Hoepting et al. [40] reported on $15 \mathrm{yr}$ results for a set of Ontario-based black spruce plantations which were repeatedly treated from age 1 to $5 \mathrm{yr}$ following planting. The best treatment, consisting of a single direct foliar application of $2 \mathrm{~kg}$ ai/ha of glyphosate, resulted in significant $(P \leq 0.05)$ gains in basal diameter and total height of $50 \%$ and $30 \%$, respectively, over untreated control plantations.

Although results from long-term empirical experiments have yet to provide a clear picture in regards to the permanency of FVM gains, the modelling approach as applied in this study, provided insight into a plausible range of yield outcomes at rotation under a conventional silvicultural regime. Results from some of the older black spruce experiments are starting to provide a preliminary perspective on the longer-term consequences of FVM treatments. Cyr and Thiffault [41] reported $22 \mathrm{yr}$ post-treatment results for black spruce plantations which were mechanically released in the second year of their development. Results from this experiment indicated that the initial diameter and height gains observed at $5 \mathrm{yr}$ post-treatment were still significant $(P \leq$ $0.05)$, although diminished in magnitude, by age 22. Significant $(P \leq 0.05)$ survival gains $(21.5 \%)$ were also evident; however they were not detected at the $5 \mathrm{yr}$ post-treatment assessment. A similar pattern of decline was also reported by Hoepting et al. [40]. Collectively, these results suggest that untreated and treated plantations follow different developmental trajectories and thus support the modelling assumptions employed in this study. Specifically, in contrast to untreated control stands, FVM-treated stands exhibit an initial acceleration in growth which dissipates in magnitude over time.
Modelling has been used to project the consequences of yield gains arising from FVM treatments given the general lack of long-term experimental response data. The efforts have involved the employment of process-based and empirical models (e.g., benchmark yield curves [42]; forest vegetation simulator [43]). The approach utilized in this study consisted of modifying the CROPLANNER simulation model in order to account for changes in height growth and survival arising from FVM treatments through adjustments to the height growth and mortality elements of the model. These modifications were consistent with the postulated long-term effects of FVM treatments: a temporary increased in the rate of stand development and a reduction in the occurrence of suppression-related mortality during the precrown closure stage of stand development. Specifically, under the assumption that the response in height growth follows a Type I pattern after FVM treatments are applied, the site-based height-age function was modified accordingly. Although empirical-based results from long-term experiments for boreal species are currently insufficient in regards to empirically testing this assumption, early remeasurement data [41] and rotation length observations from other forest regions [44] do not contradict the hypothesis that FVM treatments result in an instantaneous increase in growth which dissipates over time.

The modeling approach proposed in this study is similar to procedure employed by South et al. [45] to project longterm yield gains of loblolly pine (Pinus taeda L.) arising from FVM treatments. A graphical age-shift adjustment was made to the volume-age production curve in which the treated stand artificially advanced along the function for a specified number of years. This adjustment reflected the FVM treatment-induced acceleration in the rate of stand development which effectively resulted in a reduction in the time required to attain a specified volume threshold. Supporting empirical data consisting of $20 \mathrm{yr}$ remeasurement data derived from 11 FVM studies revealed that the percentage difference in merchantable volume production between control and treated stands declined with age.

In addition to the Type I response in which the carrying capacity of a site is not increased due to treatment, Type II and III responses patterns in which carrying capacity increases and decreases, respectively, have been postulated for some specific species and site conditions. Richardson [44] hypothesized that radiata pine (Pinus radiata D. Don) may exhibit a Type II pattern in situations where a competitor which is tolerant to low light conditions and competes aggressively for below ground resources (i.e., symmetric competition for moisture and nutrients) remains in the control stand until rotation. This ultimately could result in the degradation of site quality and result in a decline in the carrying capacity of the untreated control stand, relative to the treated stand. Conversely, a Type III pattern could conceivably arise in cases where a light intolerant competitor rapidly establishes itself on a control site and acquires the below ground resources that would normally be lost to leaching. Subsequently at the time of crown closure, the competitor could release these conserved nutrients upon decomposition, resulting in an increase in the rate of stand development. Thus in this situa- 
tion, productivity may actually increase in the untreated stand relative to the treated stand. However, irrespective of these theoretical alternative response patterns, the existing empirical evidence largely supports the applicability of the Type I response pattern for modeling the yield consequences of FVM treatments (e.g., [41, 44]).

The modelled increase in survival until the point of crown closure for the treated stands assumes that the benefit of avoiding mortality of the crop tree species will only last until crown closure occurs. Considering that the principal competition on boreal sites has been characterized as consisting of short-lived ericaceae species (e.g., Kalmia angustrifolia L., Labrador tea (Rhododendron groenlandicum (Oeder) K. A. Kron and Judd), and blueberries (Vaccinium spp.)) which compete symmetrically for below-ground resources, and herbaceous forbs (e.g., fireweed (Epilobium angustifolium L.), small shrubs (e.g., red raspberry (Rubus idaeus L.), and small trees (e.g., mountain maple (Acer spicatum Lamb.), beaked hazel (Corylus cornuta Marsh.), and pin cherry (Prunus pensylvanica L. F.)) which compete asymmetrically for above-ground resources $[16,46]$, this was a reasonable assumption. Given that long-term experimental results are lacking to test this assumption and early survival gains reported during the pre-crown closure period are often characterized by considerable variation in terms of their magnitude and duration (e.g., $[29,41,47]$ ), the use of a constant but developmental-limited mortality rate (until crown closure) to account for survival differences, was considered a prudent approach.

The CROPLANNER simulation model used in this study does not explicitly account for the potential effect of competing vegetation on succession patterns within untreated stands. Basically, the model assumes that once crown closure is achieved, the competitors will be eventually shaded out and the untreated stand will return to a mostly monospecific condition (e.g., $>90 \%$ black spruce in terms of basal area). Consequently, this assumption is only realistic if the population of competitors is comprised of short-lived ericaceous species, herbaceous forbs, small shrubs, and (or) small trees. Conversely, if woody competitors remained within the control plantations following crown closure (e.g., $\geq 10 \%$ of the basal area composed of interspecific woody competitors, such as trembling aspen (Populus tremuloides (Michx.)) and white birch (Betula papyifera (Marsh.)), then the uses of the model would result in an under estimation of the effects the FVM treatments. Bell et al. [42] attempted to project the long-term effects of FVM treatments on black spruce volume productivity using observed differences in net merchantable volume, diameter, density, and species composition between treated and control stands at $10 \mathrm{yrs}$ post-treatment, in combination with a set of empirical benchmark yield curves. The assumption that species composition remained static from age 10 to a rotation age $(60 \mathrm{yr})$ was implemented. The results suggested that the large differences in species composition at year 10 greatly influence the merchantable yield outcomes at year 60: the preferred net merchantable conifer volume on the treated plots was $152 \%$ (minimum-maximum: -55 to $670 \%$ ) greater than that projected for the control plots
( $n$, values derived from the Nipigon Hele and Nipigon Corrigal experiments as reported in Table 7 of Bell et al. [42]). Similarly, Homagain et al. [43] employed the forest vegetation simulator in combination with a bucking algorithm to project $70 \mathrm{yr}$ rotational effects of FMV treatments, in order to conduct a cost and benefit analysis for these same two experiments. Although the projection period differed by only 10 years between the studies (60 yr in Bell et al. [42] versus $70 \mathrm{yr}$ in Homagain et al. [43]), the estimated merchantable yields were different. Homagain et al. [43] reported that the net merchantable preferred conifer volume on the treated plots was only $29 \%$ (minimum-maximum: $22-41 \%$ ) greater than that projected for the control plots ( $n$, values derived from the Nipigon Hele and Nipigon Corrigal experiments as reported in Table 3 of Homagain et al. [43]). These differences highlight the variation in outcomes that can arise when using different modeling approaches and assumptions. The approach utilized in this study, in which FVM treatment effects are explicitly modelled in terms of height and survival gains based on a Type I response pattern, represents an alternative approach to modeling the long-term effects of FVM treatments. Nevertheless, although modeling provides a plausible range of outcomes to FVM treatments, the rotational consequences of FVM treatments will not be fully ascertained until remeasurement data from long-term experiments become available.

\section{Conclusion}

The results and associated inferences of this study clearly illustrated the important role FVM treatments can play in minimizing the negative yield consequences of interspecific competition on black spruce. Consequential gains in basal diameter, total height, stem volume, and survival were evident within the initial post-treatment period and when, projected over the rotation, resulted in gains in stand-level operability. However, the modelling assumptions used in these long-term projections still require empirical validation and hence these rotational effects should be considered tentative. Remeasurement data derived from long-term experiments are required to fully understand the growth response pattern and the magnitude of the yield gains possible through FVM treatments. Irrespective of the evolving shift from phytocidal chemicals to various nonchemical treatment alternatives [17, 47], the challenge of maintaining coniferous forest cover on recently distributed sites, attaining statutory-defined free-togrow status, and ensuring long-term productivity, suggests that FVM will continue to be an essential silvicultural treatment option.

\section{Acknowledgments}

The author expresses his appreciation to the Forestry Research Partnership and the Ontario Living Legacy Trust, for fiscal support.

\section{References}

[1] T. Erdle, "Forest level effects of stand level treatments: using silviculture to control the AAC via the allowable cut effect," in 
Expert Workshop on the Impact of Intensive Forest Management on the Allowable Cut, P. F. Newton, Ed., pp. 19-30, Forestry Research Partnership, Canadian Ecology Centre, Mattawa, Ontario, Canada, 2001.

[2] P. F. Newton, "Systematic review of yield responses of four North American conifers to forest tree improvement practices," Forest Ecology and Management, vol. 172, no. 1, pp. 2951, 2003.

[3] P. F. Newton and I. G. Amponsah, "Systematic review of shortterm growth responses of semi-mature black spruce and jack pine stands to nitrogen-based fertilization treatments," Forest Ecology and Management, vol. 237, no. 1-3, pp. 1-14, 2006.

[4] P. F. Newton, "Meta-analytical trends in diameter response of black spruce and jack pine to pre-commercial thinning," in Proceedings of the 2nd International Conference on Forest Measurements and Quantitative Methods and Management \& The 2004 Southern Mensurationists Meeting, C. J. Cieszewski and M. Strub, Eds., pp. 217-223, Fiber Supply Assessment, Center for Forest Business, Warnell School of Forestry and Natural Resources, University of Georgia, Athens, Ga, USA, 2006.

[5] P. F. Newton, "Development of an integrated decision-support model for density management within jack pine stand-types," Ecological Modelling, vol. 220, no. 23, pp. 3301-3324, 2009.

[6] P. F. Newton, "A decision-support system for density management within upland black spruce stand-types," Environmental Modelling \& Software. In revision.

[7] J. D. Walstad and P. J. Kuch, "Introduction to forest vegetation management," in Vegetation Management For Conifer Production, J. D. Walstad and P. J. Kuch, Eds., pp. 3-14, John Wiley \& Sons, Toronto, Canada, 1987.

[8] R. G. Wagner, K. M. Little, B. Richardson, and K. McNabb, "The role of vegetation management for enhancing productivity of the world's forests," Forestry, vol. 79, no. 1, pp. 57-79, 2006.

[9] F. W. Bell, N. Thiffault, K. Szuba, N. J. Luckai, and A. Stinson, "Synthesis of silviculture options, costs, and consequences of alternative vegetation management practices relevant to boreal and temperate conifer forests: introduction," Forestry Chronicle, vol. 87, no. 2, pp. 155-160, 2011.

[10] D. G. Thompson and D. G. Pitt, "A review of Canadian forest vegetation management research and practice," Annals of Forest Science, vol. 60, no. 7, pp. 559-572, 2003.

[11] J. D. Walstad, M. Newton, and D. H. Gjerstad, "Overview of vegetation management alternatives," in Forest Vegetation Management For Conifer Production, J. D.and Walstad and P. J. Kuch, Eds., pp. 157-200, John Wiley \& Sons, Toronto, Ontario, Canada, 1987.

[12] F. W. Bell, K. R. Ride, M. L. St-Amour, and M. Ryans, "Productivity, cost, efficacy and cost effectiveness of motor-manual, mechanical, and herbicide release of boreal spruce plantations," Forestry Chronicle, vol. 73, no. 1, pp. 39-46, 1997.

[13] F. W. Bell, R. A. Lautenschlager, R. G. Wagner, D. G. Pitt, J. W. Hawkins, and K. R. Ride, "Motor-manual, mechanical, and herbicide release affect early successional vegetation in northwestern Ontario," Forestry Chronicle, vol. 73, no. 1, pp. 61-68, 1997.

[14] J. A. Matarczyk, A. J. Willis, J. A. Vranjic, and J. E. Ash, "Herbicides, weeds and endangered species: management of bitou bush (Chrysanthemoides monilifera ssp. rotundata) with glyphosate and impacts on the endangered shrub, Pimelea spicata," Biological Conservation, vol. 108, no. 2, pp. 133-141, 2002.
[15] V. Roy, N. Thiffault, and R. Jobidon, "Maîtrise intégrée de la végétation au Québec (Canada) : une alternative efficace aux phytocides chimiques," Note de recherche forestière no 123, Direction de la recherche forestière, Gouvernement du Québec, Québec, Canada, 2003.

[16] N. Thiffault and V. Roy, "Living without herbicides in Québec (Canada): historical context, current strategy, research and challenges in forest vegetation management," European Journal of Forest Research, vol. 130, no. 1, pp. 117-133, 2011.

[17] N. McCarthy, N. S. Bentsen, I. Willoughby, and P. Balandier, "The state of forest vegetation management in Europe in the 21 st century," European Journal of Forest Research, vol. 130, no. 1, pp. 7-16, 2011.

[18] D. G. Pitt, C. S. Krishka, F. W. Bell, and A. Lehela, "Five-year performance of three conifers stock types on fine sandy loam soils treated with hexazinone," Northern Journal of Applied Forestry, vol. 16, pp. 72-81, 1999.

[19] P. E. Reynolds and M. J. Roden, "Hexazinone site preparation improves black spruce seedling survival and growth," Forestry Chronicle, vol. 71, pp. 426-433, 1995.

[20] P. E. Reynolds and M. J. Roden, "Site preparation with sulfonylurea herbicides improves black spruce seedling growth," Forestry Chronicle, vol. 72, no. 1, pp. 80-85, 1996.

[21] J. E. Wood and F. W. von Althen, "Establishment of white spruce and black spruce in boreal Ontario: effects of chemical site preparation and post-planting weed control," Forestry Chronicle, vol. 69, no. 5, pp. 554-560, 1993.

[22] B. Sutherland, I. K. Morrison, F. F. Foreman, and P. E. Reynolds, "Response of black spruce seedlings and competitive vegetation following chemical and mechanical site preparation on a boreal mixedwood site in northern Ontario," in Proceedings of the 3th International Conference on Forest Vegetation Management, G. Wagner and D. G. Thompson, Eds., pp. 326328, Ontario Forest Research Institute, Ministry of Natural Resources, Government of Ontario, Ontario, Canada, 1998, Forest Research Information Paper no. 141.

[23] B. Sutherland and F. R. Foreman, "Black spruce and vegetation response to chemical and mechanical site preparation on a boreal mixedwood site," Canadian Journal of Forest Research, vol. 30, no. 10, pp. 1561-1570, 2000.

[24] R. Jobidon, F. Trottier, and L. Charette, "Dégagement chimique ou manuel de plantations de l'épinette noire? Étude de cas dans la domaine de la sapinière à bouleau blanc au Québec," Forestry Chronicle, vol. 75, no. 6, pp. 973-979, 1999.

[25] R. G. Wagner, G. H. Mohammed, and T. L. Noland, "Critical period of interspecific competition for northern conifers associated with herbaceous vegetation," Canadian Journal of Forest Research, vol. 29, no. 7, pp. 890-897, 1999.

[26] R. Jobidon and L. Charette, "Effets, après 10 ans, du dégagement manuel simple ou répété et de al période de coupe de la végétation de compétition sur la croissance de l'épinette noire en plantation," Canadian Journal of Forest Research, vol. 27, no. 12, pp. 1979-1991, 1997.

[27] J. E. Wood and E. G. Mitchell, "Silvicultural treatments for black spruce establishment in boreal Ontario: effects of weed control, stock type, and planting season," NODA/NFP Technical Report TR-10, Great Lakes Forestry Centre, Canadian Forest Service number, Department of Natural Resources, Government of Canada, Sault Ste. Marie, Ontario, Canada, 1995.

[28] G. Robinson, S. Wetzel, and D. Burgess, "Remeasurement of Cartier Lake and Foleyet site preparation experiments," Interim Report, Forestry Research Partnership, Canadian Ecology Centre, Ontario, Canada, 2001. 
[29] D. G. Pitt, R. G. Wagner, and W. D. Towill, "Ten years of vegetation succession following ground-applied release treatments in young black spruce plantations," Northern Journal of Applied Forestry, vol. 21, no. 3, pp. 123-134, 2004.

[30] J. S. Rowe, Forest Regions of Canada, Canadian Forestry Service, Department Environment, Government of Canada, Ottawa, Ontario, Canada, 1972.

[31] L. V. Hedges and I. Olkin, Statistical Methods for Meta-Analysis, Academic Press, New York, NY, USA, 1995.

[32] L. V. Hedges, J. Gurevitch, and P. S. Curtis, "The meta-analysis of response ratios in experimental ecology," Ecology, vol. 80, no. 4, pp. 1150-1156, 1999.

[33] P. Snowdon, "Modeling type 1 and type 2 growth responses in plantations after application of fertilizer or other silvicultural treatments," Forest Ecology and Management, vol. 163, no. 1-3, pp. 229-244, 2002.

[34] C. Y. Xie and A. D. Yanchuk, "Breeding values of parental trees, genetic worth of seed orchard seedlots, and yields of improved stocks in British Columbia," Western Journal of Applied Forestry, vol. 18, no. 2, pp. 88-100, 2003.

[35] S. Fu, F. W. Bell, and H. Y. H. Chen, "Long-term effects of intensive silvicultural practices on productivity, composition, and structure of northern temperate and boreal plantations in Ontario, Canada," Forest Ecology and Management, vol. 241, no. 1-3, pp. 115-126, 2007.

[36] W. H. Carmean, G. Hazenberg, and K. C. Deschamps, "Polymorphic site index curves for black spruce and trembling aspen in northwest Ontario," Forestry Chronicle, vol. 82, no. 2, pp. 231-242, 2006.

[37] P. F. Newton and P. A. Jolliffe, "Aboveground dry matter partitioning responses of black spruce to directional-specific indices of local competition," Canadian Journal of Forest Research, vol. 33, no. 10, pp. 1832-1845, 2003.

[38] R. G. Wagner, "Competition and critical-period thresholds for vegetation management decisions in young conifer stands," Forestry Chronicle, vol. 76, no. 6, pp. 961-968, 2000.

[39] R. E. Stewart, L. L. Gross, and B. H. Honkola, "Effects of competing vegetation on forest trees: a bibliography with abstracts," General Technical Report WO-43, Department of Agriculture Forest Service, Washington, DC, USA, 1984.

[40] M. K. Hoepting, R. G. Wagner, J. McLaughlin, and D. G. Pitt, "Timing and duration of herbaceous vegetation control in northern conifer plantations: 15th-year tree growth and soil nutrient effects," Forestry Chronicle, vol. 87, no. 3, pp. 398-413, 2011.

[41] G. Cyr and N. Thiffault, "Long-term black spruce plantation growth and structure after release and juvenile cleaning: a 24year study," Forestry Chronicle, vol. 85, no. 3, pp. 417-426, 2009.

[42] F. W. Bell, J. Dacosta, M. Penner et al., "Longer-term volume trade-offs in spruce and jack pine plantations following various conifer release treatments," Forestry Chronicle, vol. 87, no. 2, pp. 235-250, 2011.

[43] K. Homagain, C. K. Shahi, N. J. Luckai, M. Leitch, and F. W. Bell, "Benefit-cost analysis of vegetation management alternatives: an Ontario case study," Forestry Chronicle, vol. 87, no. 2, pp. 260-273, 2011.

[44] B. Richardson, "Vegetation management practices in plantation forests of Australia and New Zealand," Canadian Journal of Forest Research, vol. 23, no. 10, pp. 1989-2005, 1993.

[45] D. B. South, J. H. Miller, M. O. Kimberley, and C. L. Vanderschaaf, "Determining productivity gains from herbaceous vegetation management with "age-shift" calculations," Forestry, vol. 79, no. 1, pp. 43-56, 2006.
[46] F. W. Bell, M. Kershaw, I. Aubin, N. Thiffault, J. Dacosta, and A. Wiensczyk, "Ecology and traits of plant species that compete with boreal and temperate forest conifers: an overview of available information and its use in forest management in Canada," Forestry Chronicle, vol. 87, no. 2, pp. 161-174, 2011.

[47] B. S. Biring, P. G. Comeau, and P. Fielder, "Long-term effects of vegetation control treatments for release of Engelmann spruce from a mixed-shrub community in Southern British Columbia," Annals of Forest Science, vol. 60, no. 7, pp. 681-690, 2003. 

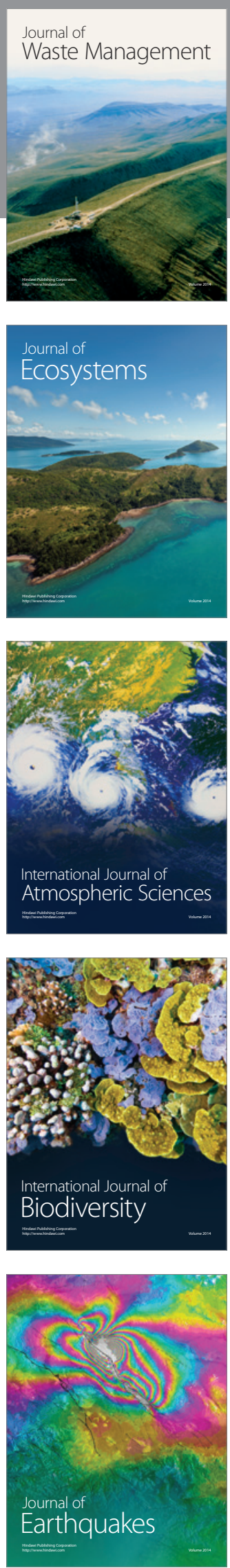
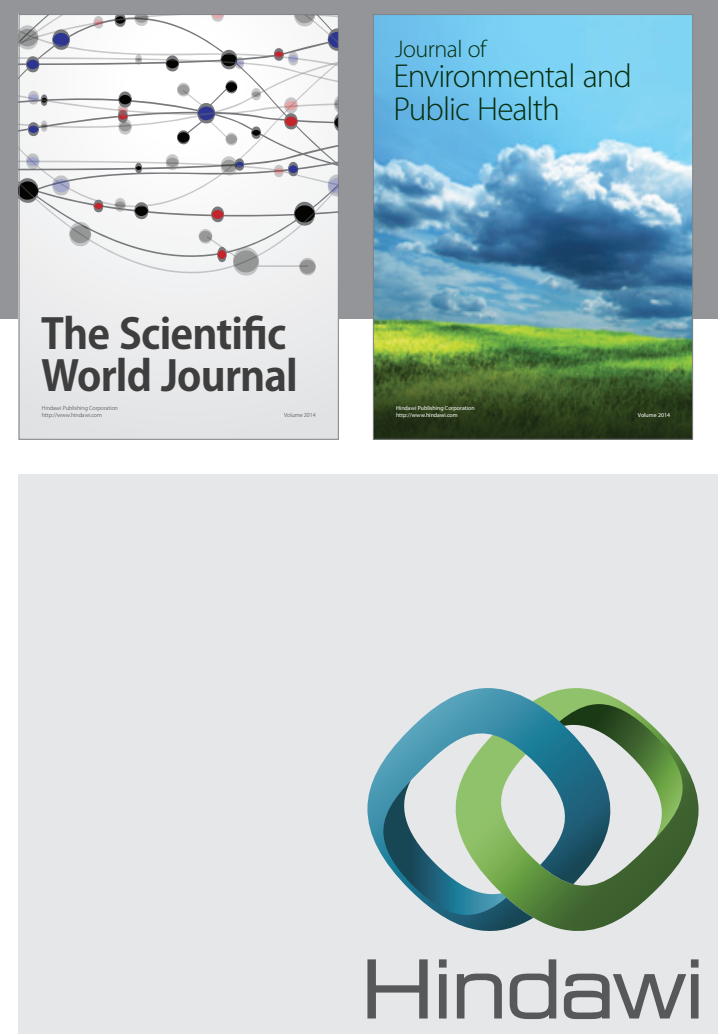

Submit your manuscripts at

http://www.hindawi.com
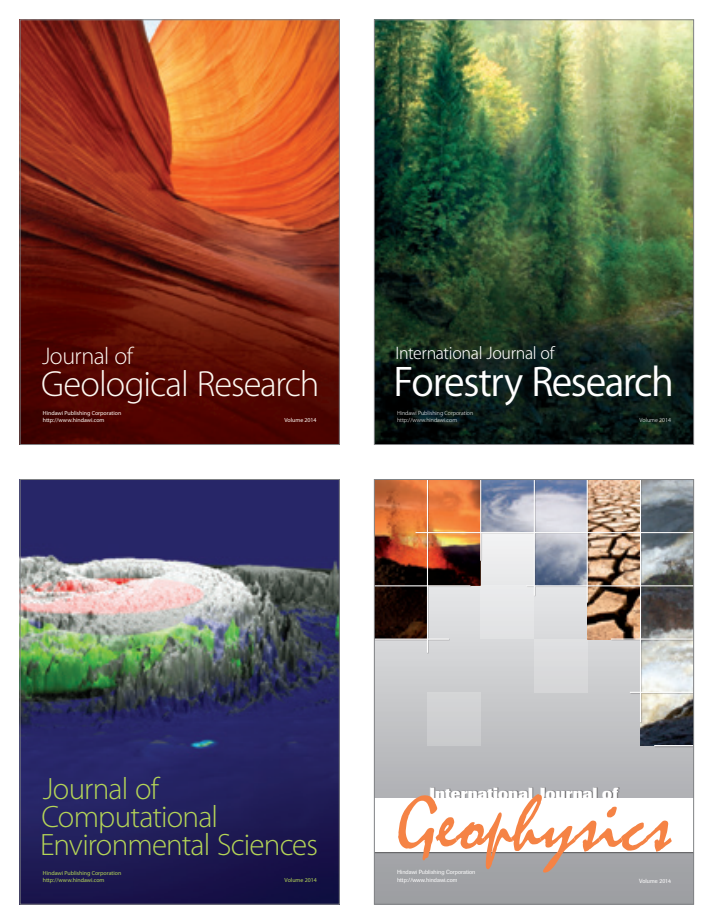
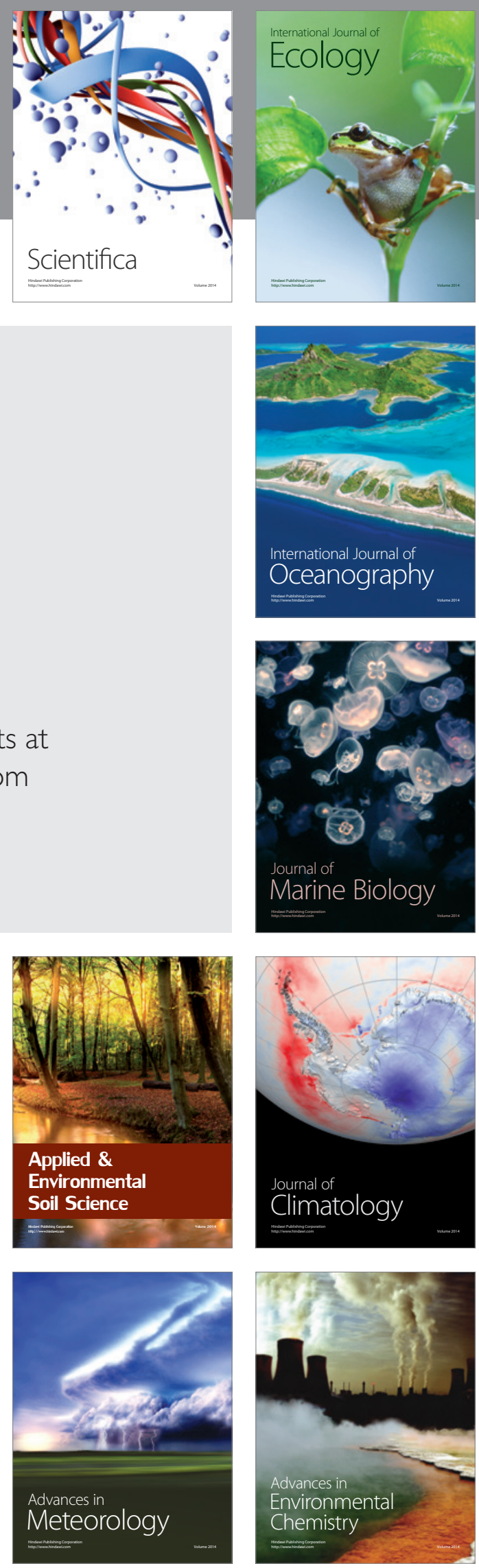